\title{
Magnetotellurics Data Application in Medium Enthalpy Geothermal Prospects
}

\author{
Denis MUTEBI ${ }^{1, \bowtie}$, Andi Agus NUR ${ }^{1}$, Agus Didit HARYANTO ${ }^{1}$, Joni WIWID ${ }^{2}$, \\ and Michael KAZINDA ${ }^{3}$ \\ ${ }^{1}$ Universitas Padjadjaran, Faculty of Geological Engineering, Bandung, Indonesia \\ ${ }^{2}$ Centre for Minerals, Coal and Geothermal Resources (PSDMBP), Bandung, Indonesia \\ ${ }^{3}$ WE Consult, Luzira, Uganda \\ $\triangle$ denis2003mutebi@gmail.com
}

\begin{abstract}
The research is aimed at delineating the reservoir and defining the geothermal system of Lili-Sepporaki through the interpretation of magnetotellurics data. Lili-Sepporaki is an andesitic-trachytic volcanic rich geothermal prospect located in western Sulawesi Province, Indonesia. In essence, hydrothermal conditions affect the properties of rocks, such as resistivity, and this can be studied using magnetotellurics, a passive electromagnetic technique. Magnetotellurics data were processed and interpreted using Phoenix and WinGLink software programs. A total of five two-dimensional resistivity models and five elevation maps were produced, and these showed a general decrease in rocks' resistivity with depth. The analysis found out that the reservoir stretches from the center, northwards. The reservoir substantially starts to be seen at a depth of $600 \mathrm{~m}$ below sea level and deepens towards the east and northwest. Another magnetotelluric survey should be carried out with more stations, mainly aimed at a three-dimensional inversion, to get a detailed geothermal model and also to study the dense, low resistive structure in the southeast.
\end{abstract}

Keywords: hydrothermal, two-dimensional, volcanic, resistivity, rocks.

\section{INTRODUCTION}

The global increase in greenhouse gases, such as Carbon dioxide, in the atmosphere, has resulted in global warming. The majority of such pollutant gases are associated with energy 
sources such as oil and coal, whose demand has been extremely elevated in the past few decades. Geothermal energy not only alleviates the challenge of increasing energy demands but also produces fewer pollutants to the environment (Ghosh and Mandal 2018). Indonesia, being strategically located on the "Ring of Fire", has a large number of volcanoes spread along the volcanic path, thus a significant geothermal potential (Prasetyo et al. 2019; Fauzi et al. 2000). Conversely, Indonesia still heavily depends on pollutant energy resources mainly hydrocarbons, as its fundamental energy source (Abfertiawan et al. 2016). All the above factors support the fact that Indonesia has the potential and need to utilize its renewable energy resources, especially the geothermal energy (Wulandari et al. 2019; Darma et al. 2010)

Lili-Sepporaki is a non-magmatic geothermal prospect located in Polewali Mandar district, western Sulawesi Province, Indonesia, composed of volcanic rocks. Sulawesi is so active tectonically owing to its location at the confluence of three tectonic plates, namely: the IndoAustralian, Eurasian and the Pacific Plates (Ünal İmer et al. 2020; Hall and Wilson 2000). Several geophysical methods have been deployed in an attempt to understand better the potential of this geothermal system for power generation. Thus, more details of the subsurface regarding the geothermal system can be unfolded through the use of the Magnetotelluric (MT), a passive electromagnetic method.

According to Unsworth (2002), information about the composition and structure of the Earth's subsurface is contained in its electrical resistivity. Naturally occurring rocks and minerals exhibit an extensive range of electrical resistivities. Subsurface fluids such as aqueous fluids (conductivity $>100 \mathrm{~S} / \mathrm{m}$ ), in interconnected rock pores have an impact on the bulk resistivities of rocks (Unsworth 2002; Hyndman and Shearer 1989). Thus, resistivity techniques can reveal the physical state and fluid content of the Earth. MT can image a clay alteration cap as a zone of low resistivity, with the higher resistivity reservoir lying below the cap (Jones and Dumas 1993; Newman et al. 2008). The resistivity anomalies are used to outline the probable extent of the geothermal field (Steingrímsson 2015). Survey results of geophysics combined with geology can lead to the location of the heat source (Monroy Parada 2016).

The main objective of this study is to delineate the geothermal reservoir through the interpretation of the magnetotelluric data in comparison with geology, geochemistry and other geophysical methods. The study is also aimed at identifying impressive geological structures that are useful not only for geothermal exploration but also for regional geological mapping.

\section{LITERATURE REVIEW}

\subsection{Geology}

Lili area is characterized dominantly by andesitic to trachytic volcanic rocks and volcanic domes (Tim Survei Terpadu 2010; Van Leeuwen 1981). The volcanic activity started during the Tertiary era, and its products have experienced intensive fracturing, which probably allows this unit to have permeability good enough to enable the passage of fluid, particularly hydrothermal fluid. Tectonic activity that occurred during Miocene-Pliocene (Hall and Wilson 2000) formed the northwest-southeast (NW-SE) trending faults (Fig. 1), and thus conduits that allow the geothermal fluid to exit through these spaces to the surface. The heat from plutonic activity is regarded as a heat source for this geothermal System. Geological formations such as Feldspathoidal Andesite (Tf), Porphyry andesite (Tp), Walimbong volcanic (Tvw) are intensively fractured while Buttu Talaya Andesite Lava (Tlt), parts of Insepaerable volcanic (Tvt), parts of Tvw and Tp are altered to chlorite and clay. Tvt and Tp extend up to a depth of almost $2000 \mathrm{~m}$ below sea level. 


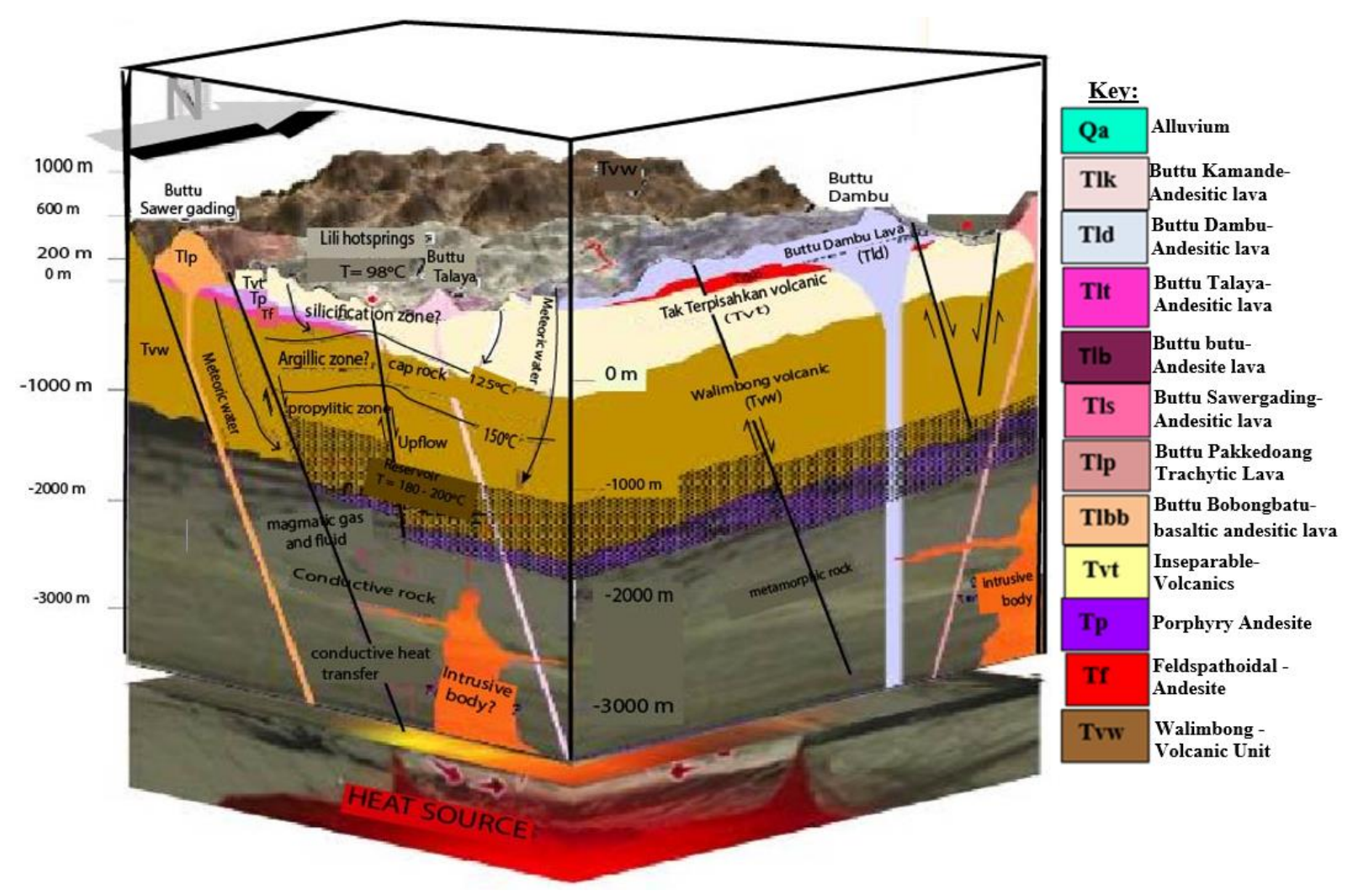

Fig. 1. Conceptual geological model of Lili-Sepporaki Prospect area showing: the hot springs, reservoir and caprock, heat source (intrusive body), and faults (black diagonal lines) (Kholid and Widodo 2011).

\subsection{Geochemistry}

The two hot springs of Lili-Sepporaki have chloride water type indicating that hot water comes from the reservoir (Tim Survei Magnetotellurik 2011). The hot springs water has a temperature of $97^{\circ} \mathrm{C}$, measured at the surface, and neutral $\mathrm{pH}$. The hot springs are in the partial equilibrium zone owing to the interaction between the hot fluid, and the rock passed through as well as mixing with meteoric surface water. Both hot springs feed in the same reservoir because of a similar $\mathrm{Cl}-\mathrm{Li}-\mathrm{B}$ ratio. The average subsurface temperature associated with the geothermal reservoir of Lili-Sepporaki is $190^{\circ} \mathrm{C}$ at depths between 800 and $1900 \mathrm{~m}$ below sea level (Kholid and Widodo 2011).

\subsection{Geophysics}

Low magnetic anomalies scattered in the west, central, northeast, southeast, northwest, and southwest parts of the investigation area (Tim Survei Magnetotellurik 2011) are attributed to hydrothermal alteration of rocks and possibly hot rocks. Habitually, ground magnetic surveys are deployed in the low-temperature fields for mapping out faults, which often control the outflow of geothermal fluid (Gupta and Roy 2007). The low residual gravity Bouguer anomalies that are spread in the north-west, middle, east, and west of the prospect area probably represent the weathered and hydrothermally altered volcanic rock formations. The high residual Bouguer anomalies that are seen in the north, center, west, and south-west are most likely andesite and basaltic andesite rocks of Tertiary age (Tim Survei Magnetotellurik 2011). Usually, residual gravity highs are interpreted to reflect structural highs, unusual geometry of fault zones, highdensity rocks, and silica deposition (Muffler and White 1969; Biehler 1971; Ross and Moore 1985; Salem et al. 2005). 


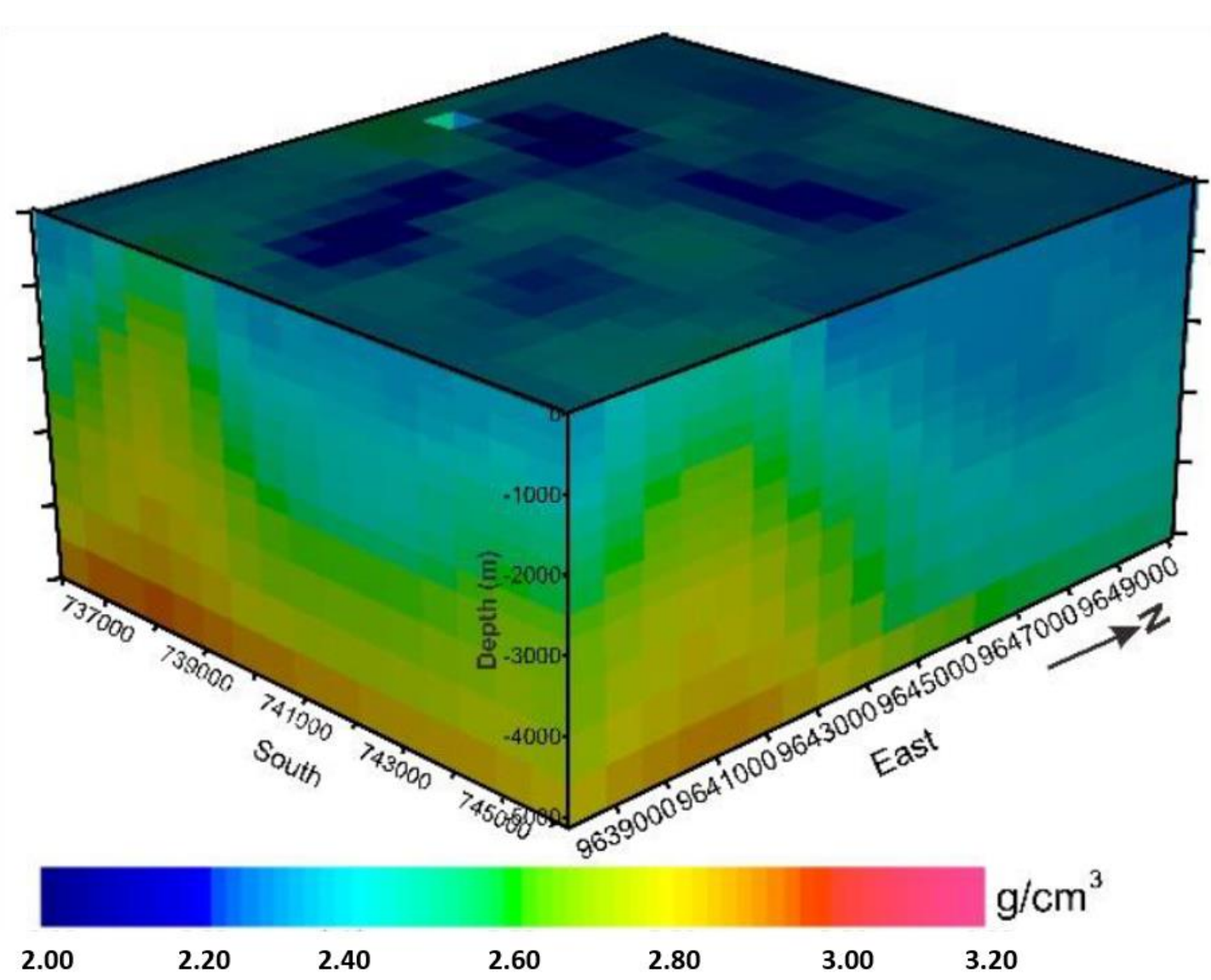

Fig. 2. 3D inversion model of Lili-Sepporaki Geothermal Prospect, showing density variation (Sihombing et al. 2019).

Furthermore, the 3D inversion model (Fig. 2) indicates a high anomaly between the south and southwest (Sihombing et al. 2019), and this is interpreted as a response from high-density igneous rocks.

\subsection{Electrical conductivity of rocks}

Like any other electric conductors, the Earth rocks also have to conduct particles such as ions and electrons (Chave and Jones 2012). A rock material with increased pore space, salinity, and concentration of conducting minerals will have its ionic conductivity significantly raised (Wright et al. 1985). Alteration of rocks into clay, under hydrothermal conditions, increases their bulk conductivity, thereby reducing the rock resistivity (Martinez-Garcia 1992; Jones and Dumas 1993; Nurhasan et al. 2006). The bulk conductivity of a rock formation can also be raised due to the presence of electrically conductive fluids that occupy the interconnected rock spaces (Simpson and Bahr 2005; Slezak et al. 2019; Chau et al. 2019). Diagenesis, compaction, and precipitation are associated with shrinking the connectivity of pore spaces, and thus reducing the conductivity of a fluid-saturated rock (Zhu et al. 1995; Chave and Jones 2012). Resistivity is the inverse of conductivity and the two quantities are indirectly proportional.

Conventionally, metamorphic and crystalline igneous rocks have resistivity values ranging between 500 and $10^{7} \Omega \mathrm{m}$, but the amount reduces to $2-500 \Omega \mathrm{m}$ for weathered igneous rocks (Oryński et al. 2019). Fluid-filled rocks occasionally have resistivities of $1 \Omega \mathrm{m}$ or less. Clay minerals, which are potential alteration products, are valued between 1 and $50 \Omega \mathrm{m}$ in terms of resistivity. 


\section{METHODOLOGY}

\subsection{Data acquisition}

MT measurements were conducted in 2011 by the Centre for Minerals, Coal, and Geothermal Resources of Indonesia (PSDMBP); station spacing was 1000-2000 m (Fig. 3), and time-lapse was 12-18 hours, evening through morning (Tim Survei Magnetotellurik 2011).

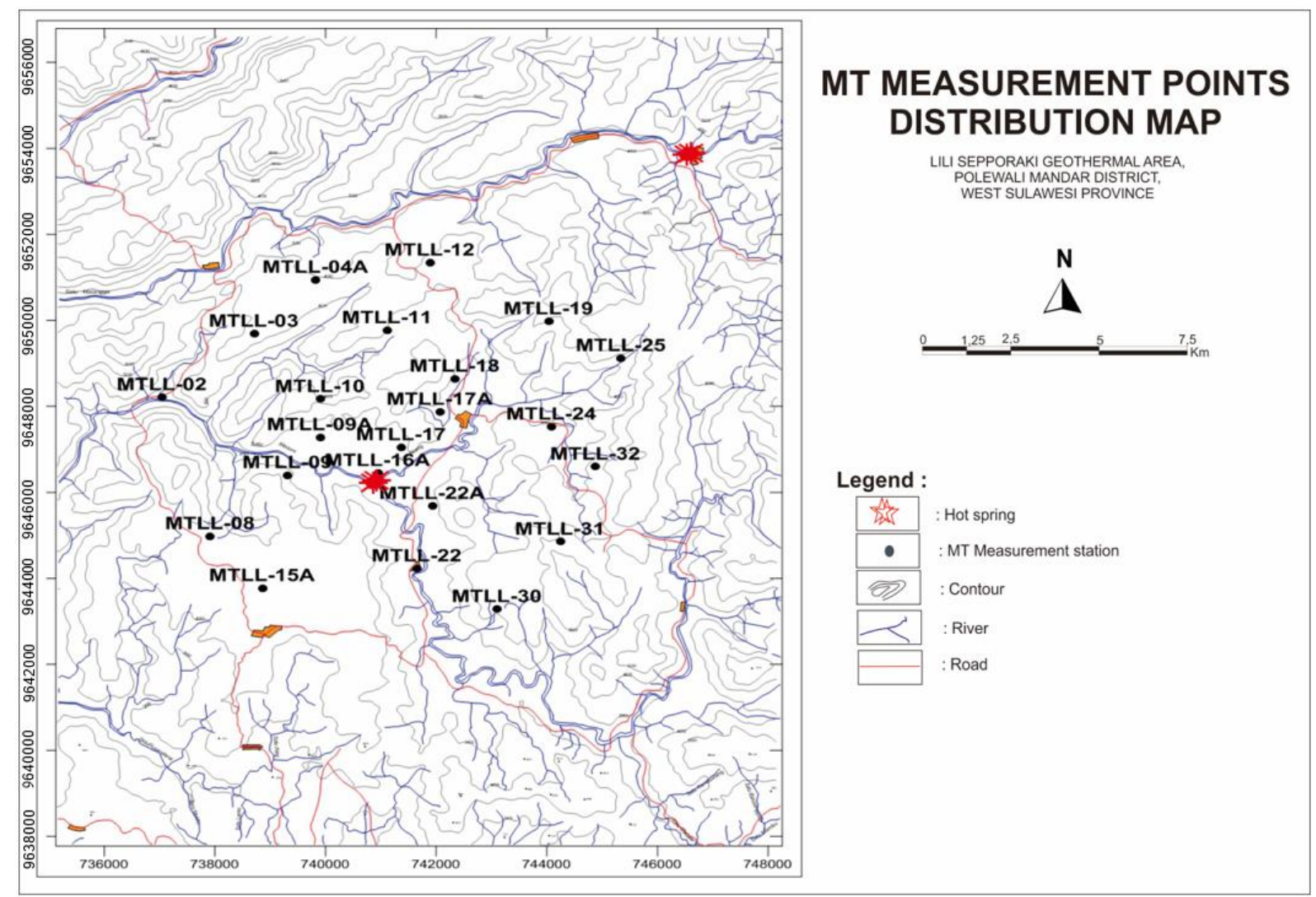

Fig. 3. A map showing the distribution of MT measurement points in Lili-Sepporaki Prospect.

\subsection{Theory of the method}

MT is a passive exploration technique that utilizes naturally occurring geomagnetic variations as a power source for electromagnetic (EM) induction in the Earth; that is to say, no current source is required, as opposed to geo-electric techniques (Simpson and Bahr 2005; Unsworth 2002).

MT technique measures fluctuations in natural Electric (E) and Magnetic (B) fields in orthogonal directions at the Earth's surface as means of determining the conductivity structure of the Earth at depth (Simpson and Bahr 2005). The source of the EM field is the interaction between the solar wind or lightening with the Earth's B field (fluctuations), thus producing E field (Simpson and Bahr 2005; Naidu 2012).

\subsection{SSMT2000 software program}

SSMT2000 program integrates the measured E and B field data into complex algorithms and gives apparent resistivity data. The MT-Editor software program displays this data. Hard time series files, calibration files, and site parameter files are input into the SSMT2000 software program; Fourier coefficients were produced intermediary and the output was MT Plot files containing multiple cross-powers for each of the frequencies analyzed. 
Most of the processing parameters were default under the SSMT2000 software. For Time series to Fourier Transforms, the "measured field" was the input data type, since this was standard processing, and "4 frequencies per octave" was the chosen output data format, aimed at higher resolution in the apparent resistivity plots and ease of interpretation of results. The default times were considered for each station and these ranged from 12 to 18 hours depending on each MT station. The maximum number of cross-powers set was 20 for each station.

\subsection{MT-Editor software program}

MT Plot files created by the SSMT2000 were input into the MT-Editor software and resistivity and phase curves plus special cross powers were produced intermediary; the static correction was carried to reverse the effect of noise by editing one frequency at a time. The edited crosspower data are then converted into industry-standard EDI files (Phoenix Geophysics 2005).

For every station auto-editing was engaged first and then manual editing of the crosspowers. The apparent resistivity plots had displayed frequencies that ranged from 500 to $0.0005 \mathrm{~Hz}$ (Fig. 4). Cross-powers with a rate of less than 0.01 were deleted or eliminated.

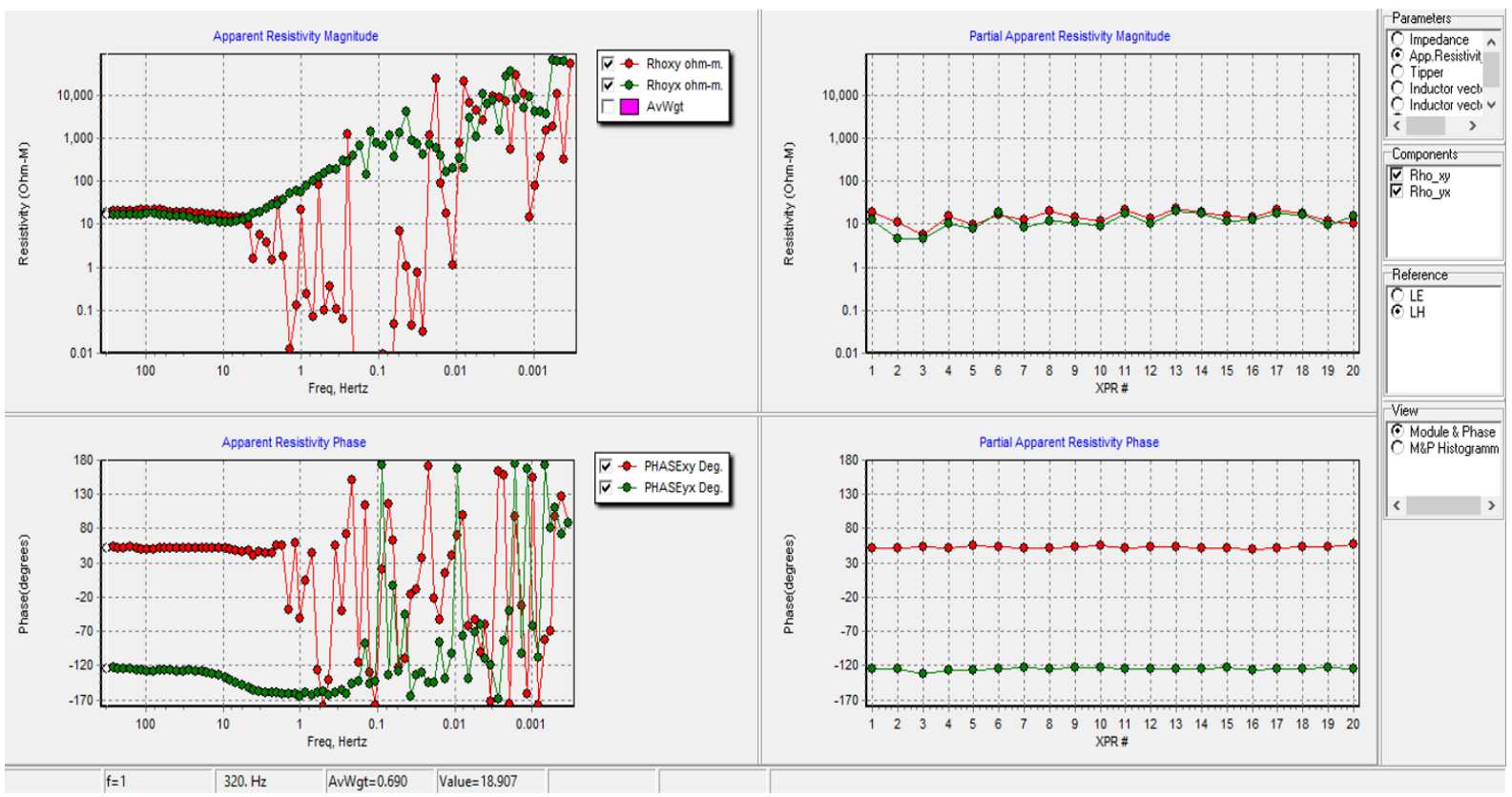

Fig. 4. A typical editing window for station MTLL-119 showing some of the set parameters on the right.

\subsection{Data interpretation using WinGLink software}

WinGLink software incorporates .edi files created by MTEditor, and at an intermediate stage, sounding editing and two-dimensional (2D) inversion were carried out. D+ smoothing was the technique used to calculate resistivity and phase smoothed curves from edited curves.

Under 2D inversion a mesh resistivity value of $100 \Omega \mathrm{m}$ was selected. Station data was used to perform the inversion. The inversion for the static shift was carried out for both the TM and TE mode, and the target color change was purple. Both the error floor and data errors were set to 5\%. The "weighting enabled" box was not checked, and the value of $\tau$ for the smoothing operator was set to 11 for all the profiles (Fig. 5). A smooth inversion was run with 30 as the minimum number of iterations. 


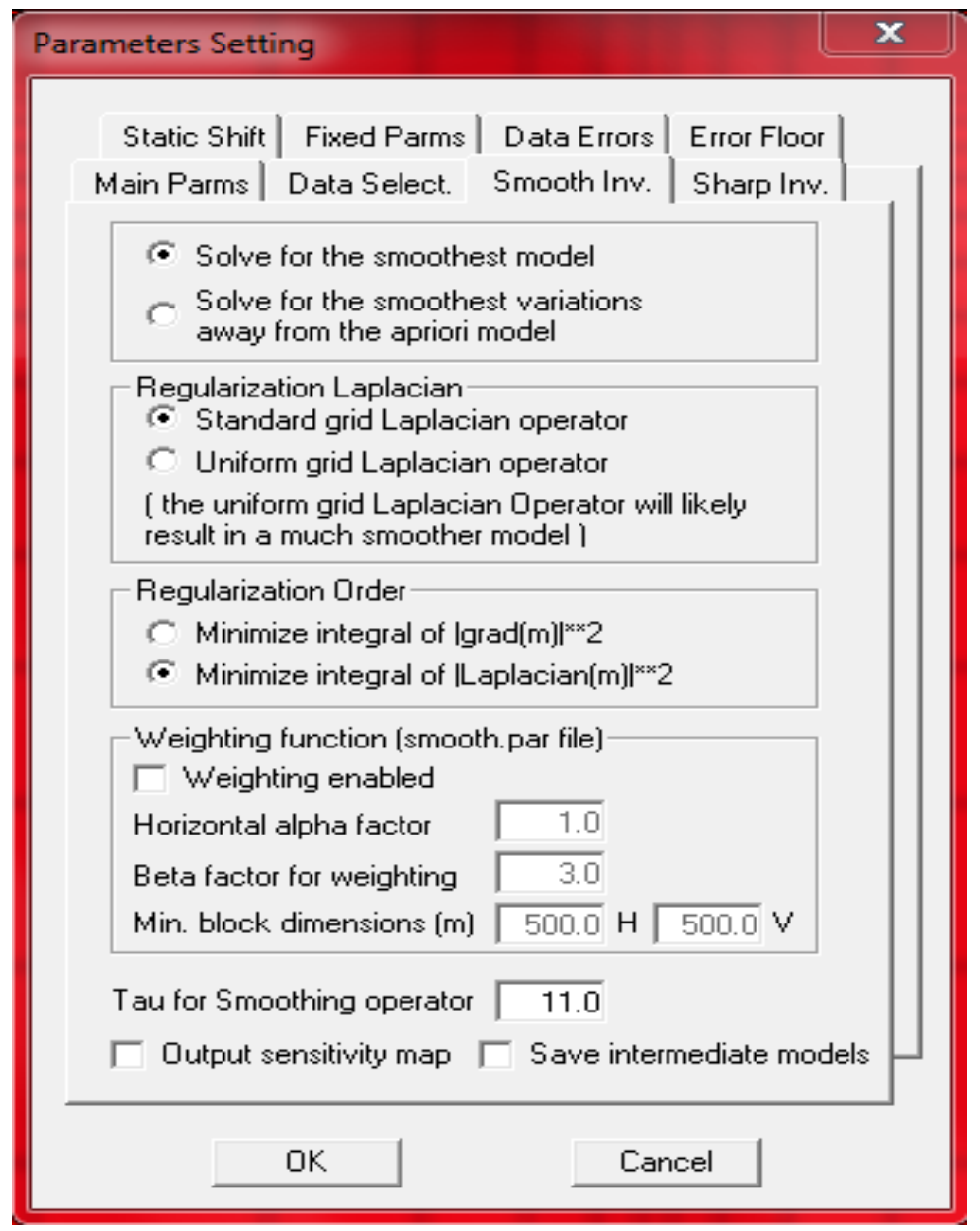

Fig. 5. Parameter Settings window showing settings that were used for Smoothing Inversion.

\section{RESULTS AND DISCUSSION}

\subsection{D resistivity models}

A total of 5 MT lines were chosen, each with several MT stations. Each of the five lines runs from the southwest towards the north-east. A 2D resistivity model was made out of each MT line. Almost every model has four resistivity zone classifications, namely: low resistivity $(<50 \Omega \mathrm{m})$, medium resistivity $(50-100 \Omega \mathrm{m})$, high resistivity $(100-250 \Omega \mathrm{m})$, and very high resistivity (> $250 \Omega \mathrm{m})$. Basing on MT and geological data analysis, a probable reservoir zone is enclosed by red dotted curved line; a cap rock is depicted by blue-dotted line enclosure, and black-dotted lines represent a fault structure on each of the models below.

\subsubsection{Line 1}

This resistivity model is composed of stations MTLL-02, MTLL-03, and MTLL-04 (Fig. 6). The low resistivity zone is distributed on the surface from northwest to southwest, and it is interpreted as a response from an inseparable volcanic unit. The medium resistivity layer is located below the low resistivity and this most likely represents the hydrothermally altered Walimbong volcanic unit. A high resistivity layer found below the medium resistivity layer is interpreted as a reservoir. The reservoir in the southwest is limited by the fault structure as seen in Fig. 6. A zone with resistivity higher than $350 \Omega \mathrm{m}$ seen at the bottom of the model is a typical response from a metamorphic rock. 

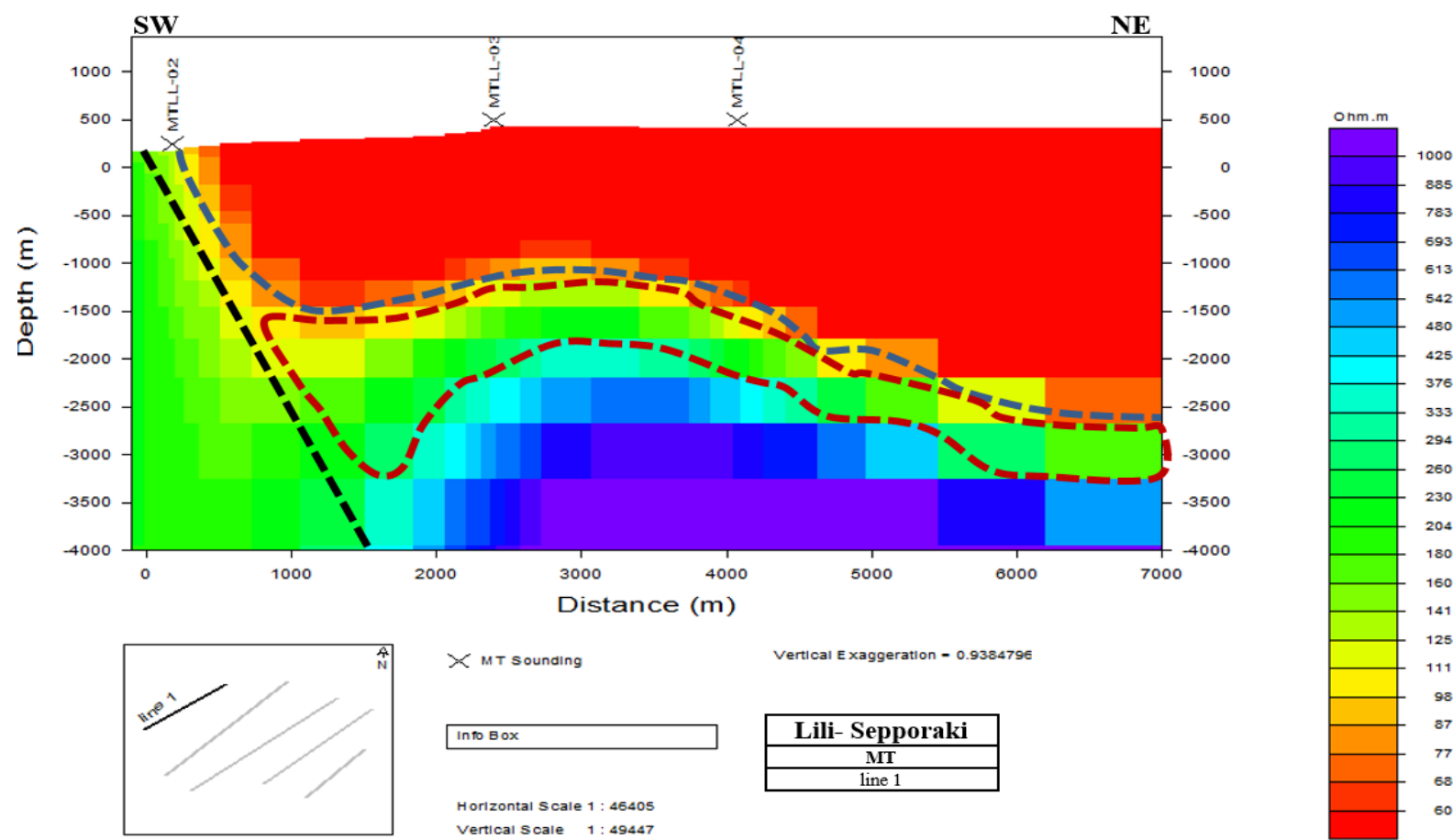

Fig. 6. 2D resistivity model of Line 1. Blue- and red-dotted curves or lines denote probable cap rock and reservoir delineations, respectively. Black dotted lines stand for fault structures.

\subsubsection{Line 2}

This model is made up of data from stations MTLL-08, MTLL-09, MTLL-09A, MTLL-10, MTLL-11, and MTLL-12 (Fig. 7). The low resistivity on the surface is probably a reflection

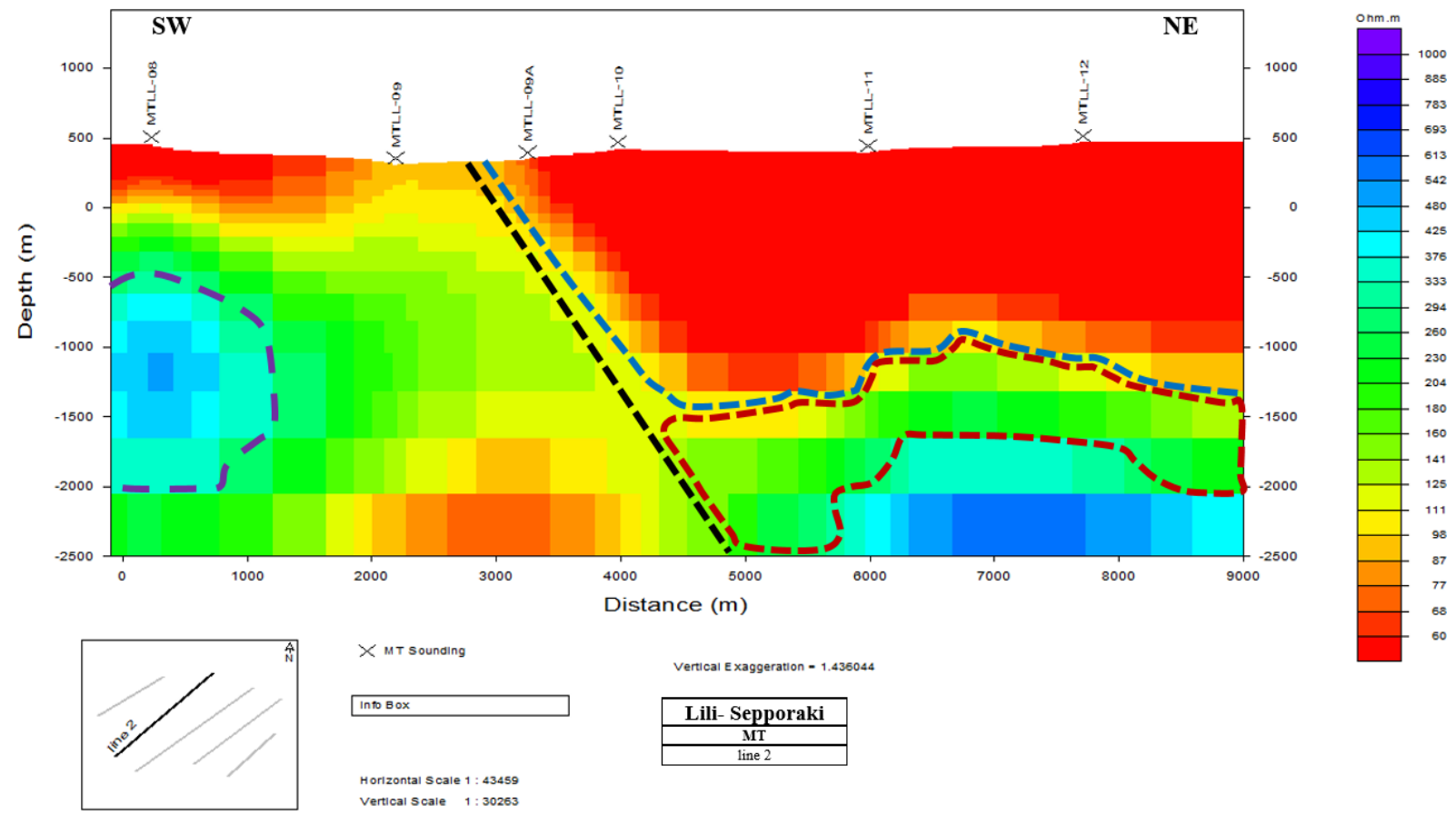

Fig. 7. 2D resistivity model of Line 2. Blue- and red-dotted curves or lines denote probable cap rock and reservoir delineations, respectively. Black dotted lines stand for fault structure while the structure enclosed by the purple dotted curve is an igneous intrusion. 
of the highly weathered inseparable volcanic. A layer of medium resistivity appears below the low resistivity and is interpreted as hydrothermally altered rocks. A high resistivity area below the medium resistivity one, between depths of 1350 and $3000 \mathrm{~m}$ below sea level, is predicted to be the reservoir in this region. A very high resistivity zone in the northeast at the bottom of the model is interpreted as a response from compact basement rocks or metamorphic rocks. The other very high resistivity zone seen in the southwest is interpreted as an igneous intrusion.

\subsubsection{Line 3}

This 2D model is made from resistivity data of stations: MTLL-15A, MTLL-16A, MTLL-17, MTLL-17A, MTLL-18, and MTLL-19 and cuts through the Lili-Sepporaki hot spring in the south-west (Fig. 8). The low resistivity anomaly distributed on the surface is probably a representation of inseparable volcanic rocks. The medium resistivity below the low resistivity is understood to be the caprock of the geothermal system; both geological and geochemical data support this and this rock is believed to be hydrothermally altered. High resistivity, which is probably a reservoir, appears below the medium resistivity layer and is limited by the fault structure around the hot spring in the south-west. A very high resistivity anomaly occupies the bottom of the model in the north-east and it is taken to be basement metamorphic rock. Another high resistivity zone (very faint blue colour) with resistivity between 250 and $350 \Omega \mathrm{m}$ is seen in the southwest of the model and this is due to the effect of the igneous intrusion.

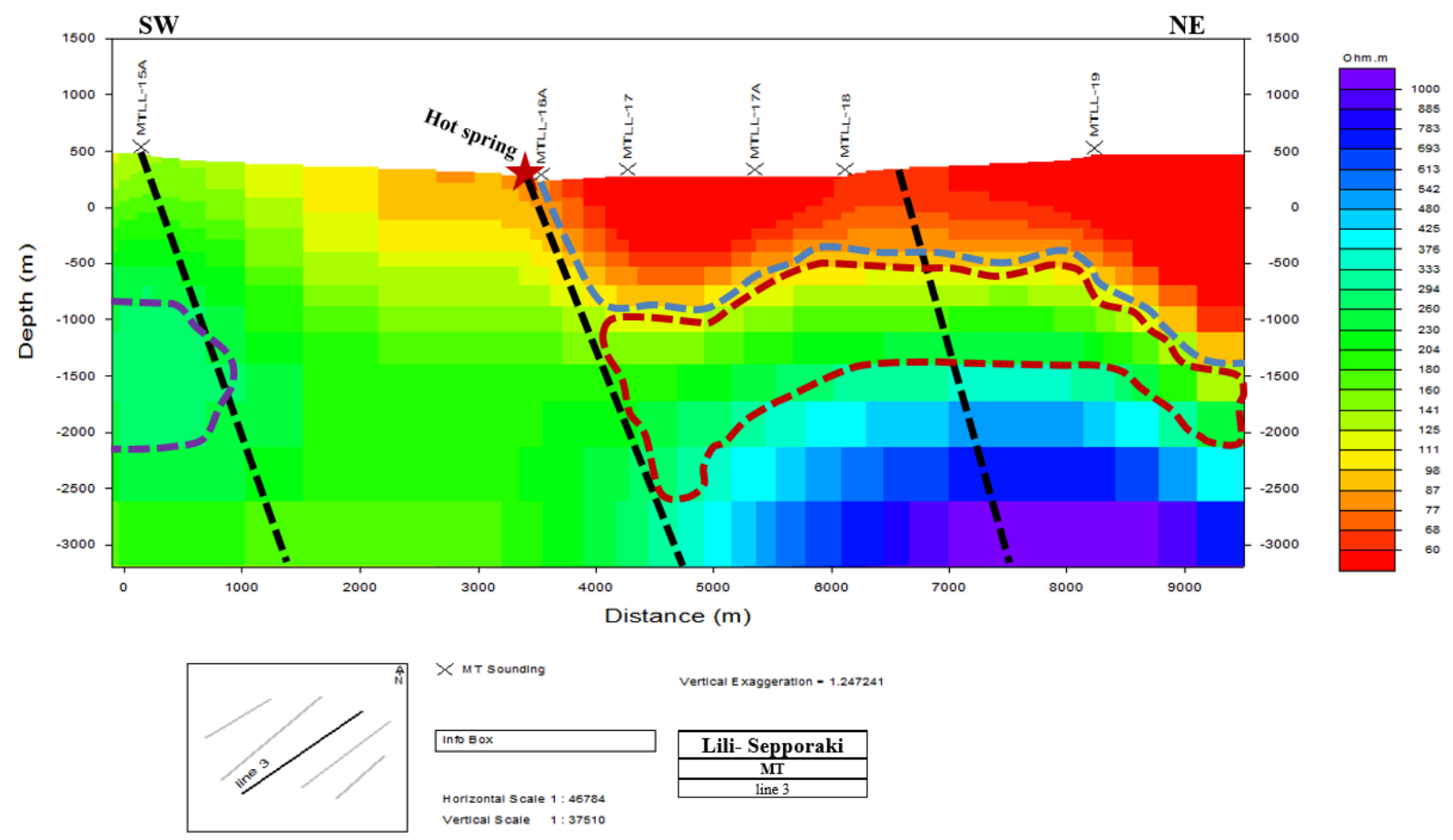

Fig. 8. 2D resistivity model of Line 3. Blue- and red-dotted curves or lines denote probable cap rock and reservoir delineations, respectively. Black dotted lines are fault structures while the structure enclosed by the purple dotted curve is an igneous intrusion. The red star represents Sepporaki hot spring.

\subsubsection{Line 4}

Stations MTLL-22, MTLL-22A, MTLL-24, and MTLL-25 make up this 2D resistivity model (Fig. 9). The low resistivity anomaly is seen throughout the surface except between stations MTLL-22 and MTLL-22A. A medium resistivity layer found below the low resistivity layer is thought of as a hydrothermally altered rock. High resistivity is found below the medium re- 

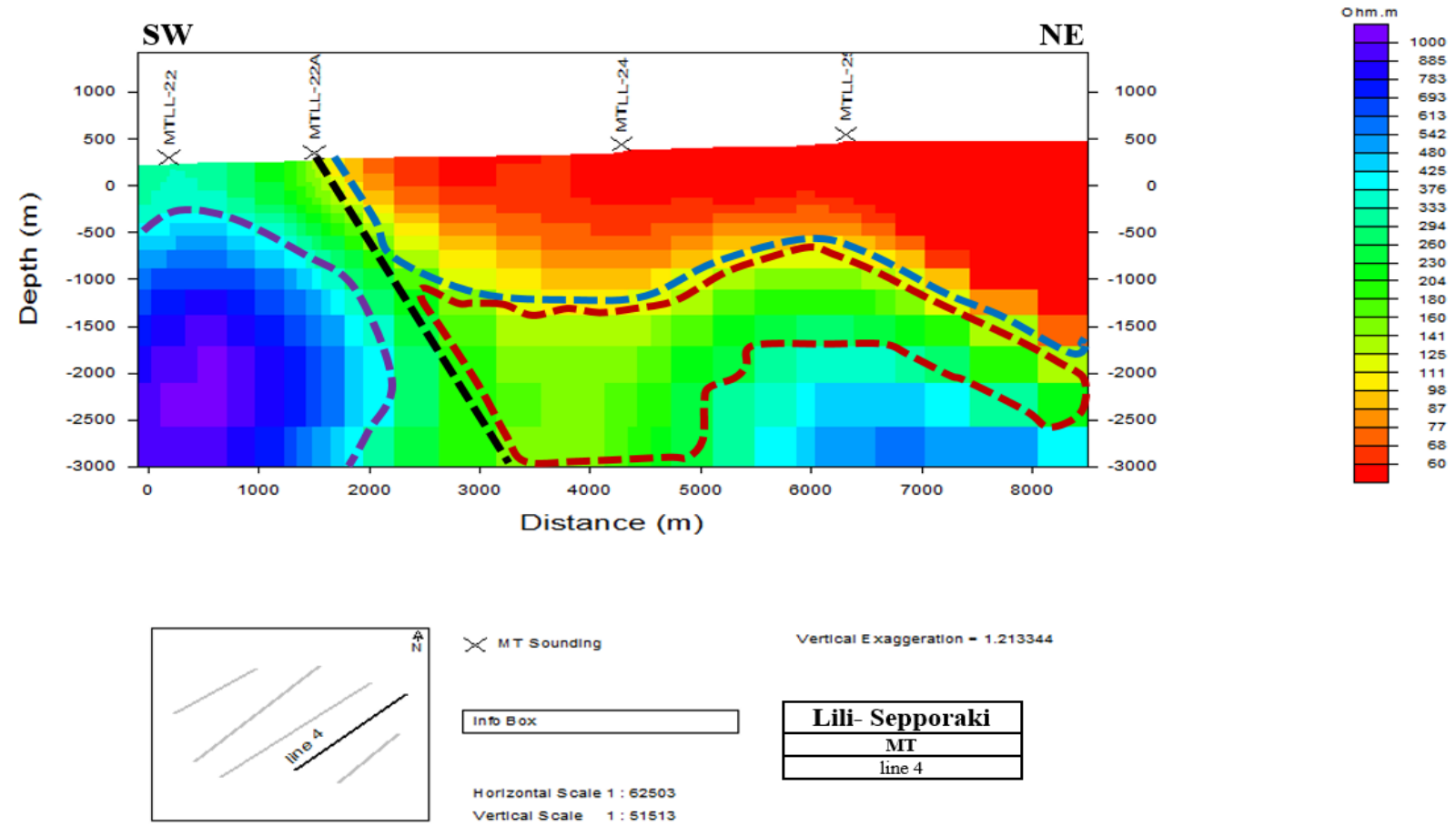

Fig. 9. 2D resistivity model of Line 4. Blue- and red-dotted curves or lines denote probable cap rock and reservoir delineations, respectively. The black dotted line stands for a fault structure while the structure enclosed by the purple dotted curve is an igneous intrusion.

sistivity and inferred as a reservoir. The fault structure in the southwest of the line is allegedly the prospect boundary in that area. A prominent structure with resistivity higher than $370 \Omega \mathrm{m}$ in the southwest is thought to be a response from a compact and massive igneous intrusion. A metamorphic basement exists at the bottom of the model in the northeast owing to resistivity with a value of more than $250 \Omega \mathrm{m}$.

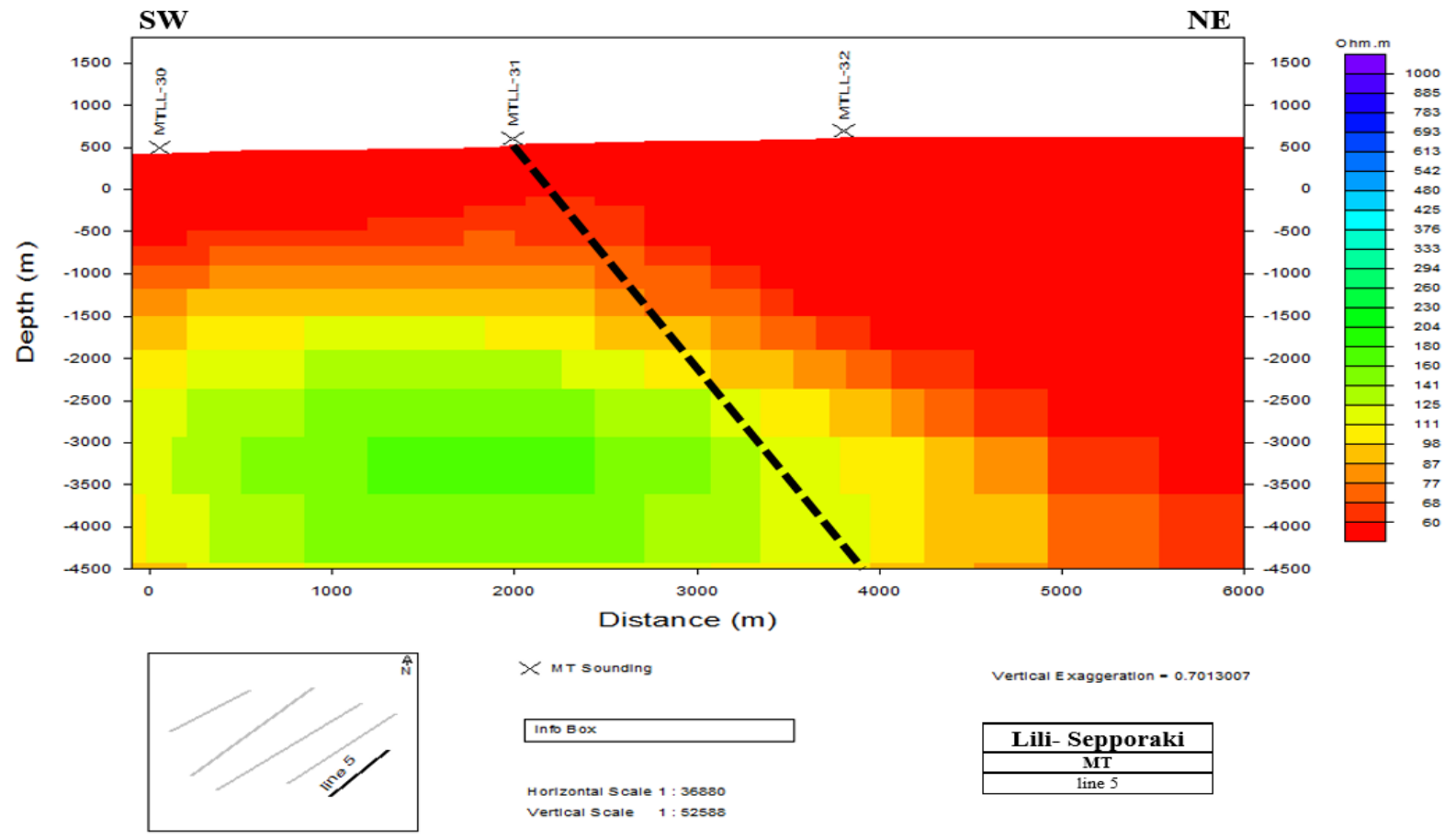

Fig. 10. 2D resistivity model of Line 5. Black dotted line represents a fault structure. 


\subsubsection{Line 5}

Points MTLL-30, MTLL-31, and MTLL-32 (Fig. 10) make up this line. A low resistivity anomaly is distributed across the surface. A medium resistivity layer appears below the low resistivity and it reaches the bottom of the model towards the northeast. A fault structure exists through station MTLL-31. High resistivity is seen at the bottom of the model from the center to the southwest.

\subsection{Elevation resistivity maps}

Results of MT data processing are displayed on elevation resistivity maps. These maps are made from $2 \mathrm{D}$ resistivity modeling data to provide detailed subsurface images. They represent elevations of $0,-500,-1000,-1500,-2000$, and $-2500 \mathrm{~m}$ a.s.l. These maps are aimed at giving a picture of a caprock and a reservoir, at depth, in the Lili-Sepporaki geothermal system. The data used to make these maps is pseudo invariant resistivity from TE and TM mode. The resistivity anomalies are divided into low resistivity $(<50 \Omega \mathrm{m})$, medium resistivity $(50-100 \Omega \mathrm{m})$, high resistivity (100-250 $\Omega \mathrm{m}$ ), and resistivity higher than $250 \Omega \mathrm{m}$.

At $0 \mathrm{~m}$ a.s.l. (Fig. 12A), low and medium resistivity dominates the most significant part of the survey area and this may be attributed to clay-rich or hydrothermally altered rocks. The magnetic survey also provides for low values in the same areas. High resistivity is seen in the southern portion of the survey area probably reflecting igneous rocks. The boundary between low and high resistivity in the south is in form of a lineament with an NW-SE orientation (Fig. 11), probably reflecting a fault structure that controls the emergence of the Sepporaki hot spring as provided for by geological data.

At a depth of $500 \mathrm{~m}$ below sea level (Fig. 12B), medium resistivity starts to appear, especially from the middle towards the north-east and this is interpreted as either clay-rich rocks of weathered volcanic rocks that act as cap rocks in the geothermal system. Resistivity higher than $250 \Omega \mathrm{m}$ that appears in the southwest is possibly a response from resistive igneous rocks.

At a depth of $1000 \mathrm{~m}$ below sea level, high resistivity replaces low and medium resistivity from the center through the northeast and this is probably the reservoir of the geothermal system (Fig. 12C).
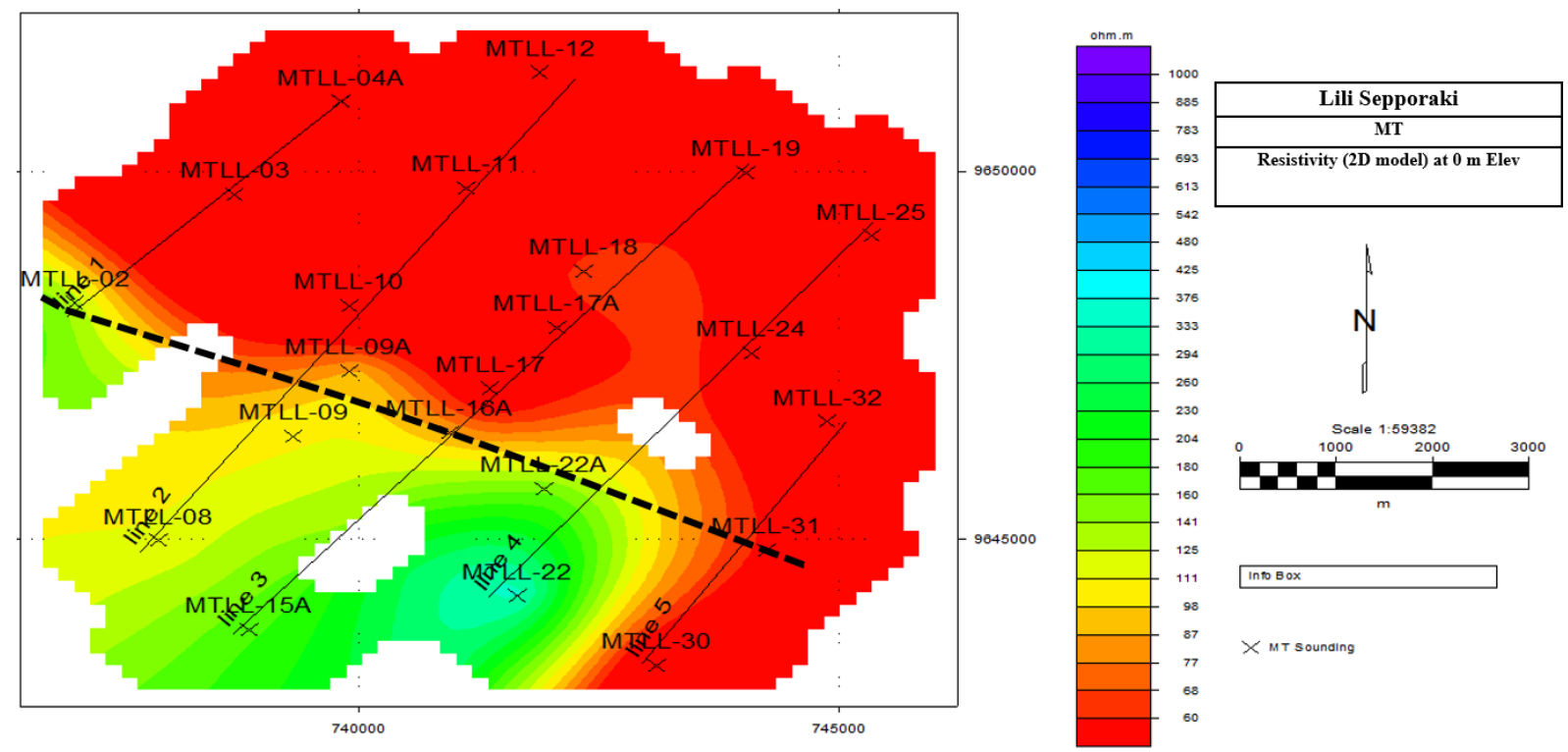

Fig. 11. Resistivity map showing the increase in contour density in the south interpreted as a structure (black-dotted line). 


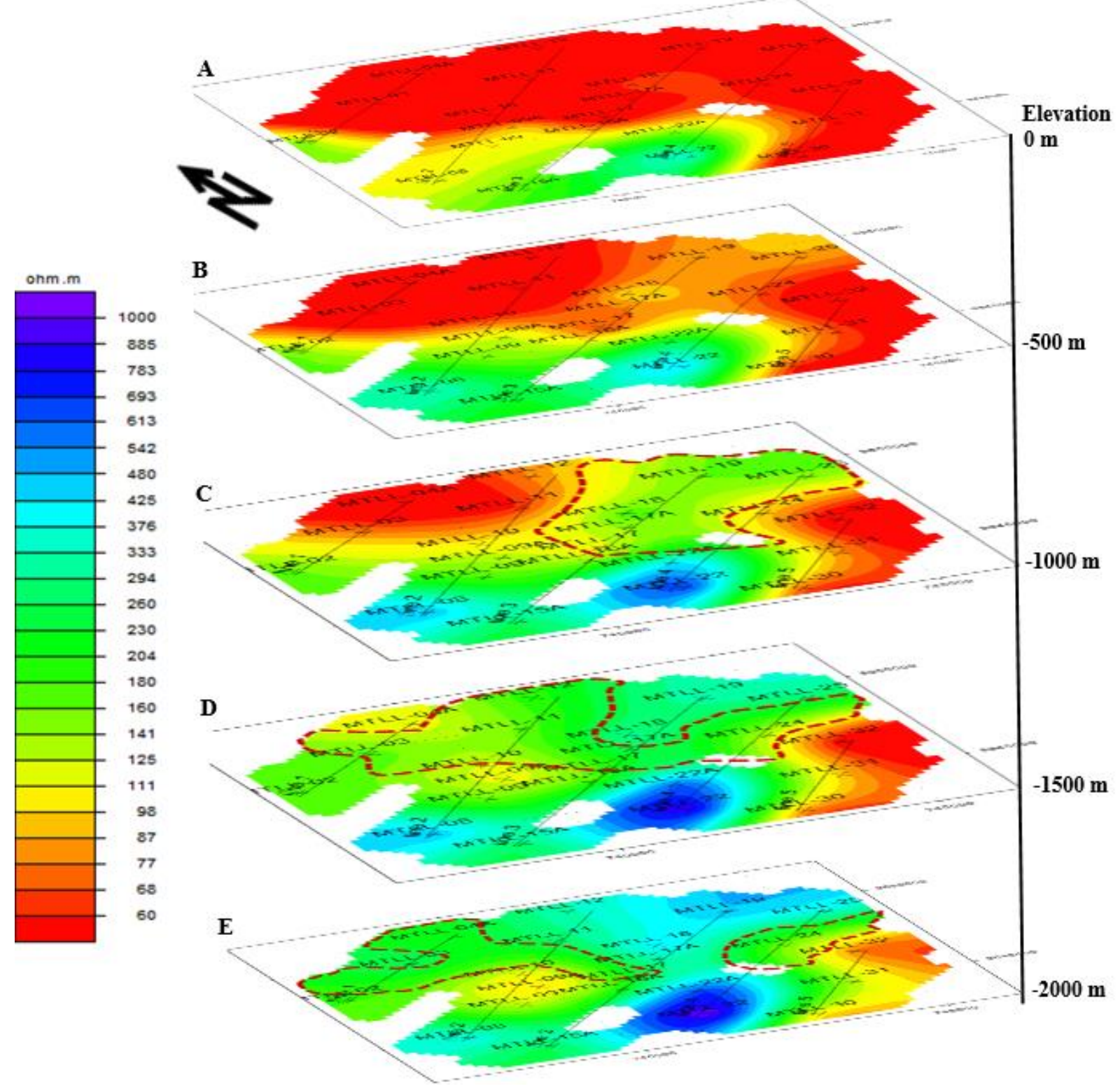

Fig. 12. Resistivity maps of Lili-Sepporaki Geothermal Prospect at different elevations. Deduced reservoir zones are enclosed within red-dotted curved lines on the bottom three maps.

At a depth of $1500 \mathrm{~m}$ below sea level, high resistivity interpreted as a reservoir sweeps up the entire northern section of the survey area (Fig. 12D). It also spreads to the center, east, and west. A resistivity higher than $300 \Omega \mathrm{m}$ appears in the north-east for the first time, which is a typical response from a basement rock, particularly a metamorphic rock owing to the geology of the area.

At a depth of $2000 \mathrm{~m}$ below sea level, the low resistivity persists in the south-east of the map, and thus possibly forms the reservoir boundary in that area (Fig. 12E). The reservoir still exists at this depth in the center, northwest, and east. Resistivity higher than $250 \Omega \mathrm{m}$ spreads further towards the center and its resistivity value increases more as compared to the previous map. This is because the basement rock gets more compact with an increase in depth. 


\subsection{Analysis}

As seen in the conceptual geological model, the reservoir is seen to appear between depths of 800 and $1900 \mathrm{~m}$ below sea level, in different parts of the prospect. MT data is also consistent with this - the deduced reservoir on Line 3 profile stretches from a depth of $600 \mathrm{~m}$ below sea level and descends beyond $2400 \mathrm{~m}$ below sea level on most of the MT profiles. Further analysis of the conceptual model provides that Tvw and Tp rock units occupy the prospect between the depths of 800 and $1900 \mathrm{~m}$ below sea level. The properties of these two units support the existence of the reservoir - they are intensively fractured according to the existing geological data. Geochemical data also suggest that the surface hot spring water comes from the reservoir owing to its chloride chemistry.

The rocks that cap the reservoir sweep up the center, northwards. These rocks are impermeable and that's why they can serve as cap rocks. Results from both magnetic and gravity surveys associate the northwest, north, center, and northeast of the prospect area with a low total magnetic anomaly and low density, respectively. Igneous rocks tend to have a high magnetic susceptibility and high density (andesite rocks). Weathering or hydrothermal alteration of the rocks in those areas account for such a low anomaly. The MT resistivity map at $\mathrm{O}$ elevation also points to weathering or alteration, as the root causes for the low resistivity anomaly in the center, northeast, and north-west. Geology of the area has it that Tvt, Tlt, and Tld occupy the surface of the prospect area. Tlt is altered to clay and chlorite, according to geology, while Tvt is silicified and also provides conduits for an inflow of meteoric water therefore most likely altered. No geological account explains whether Tld is altered or not.

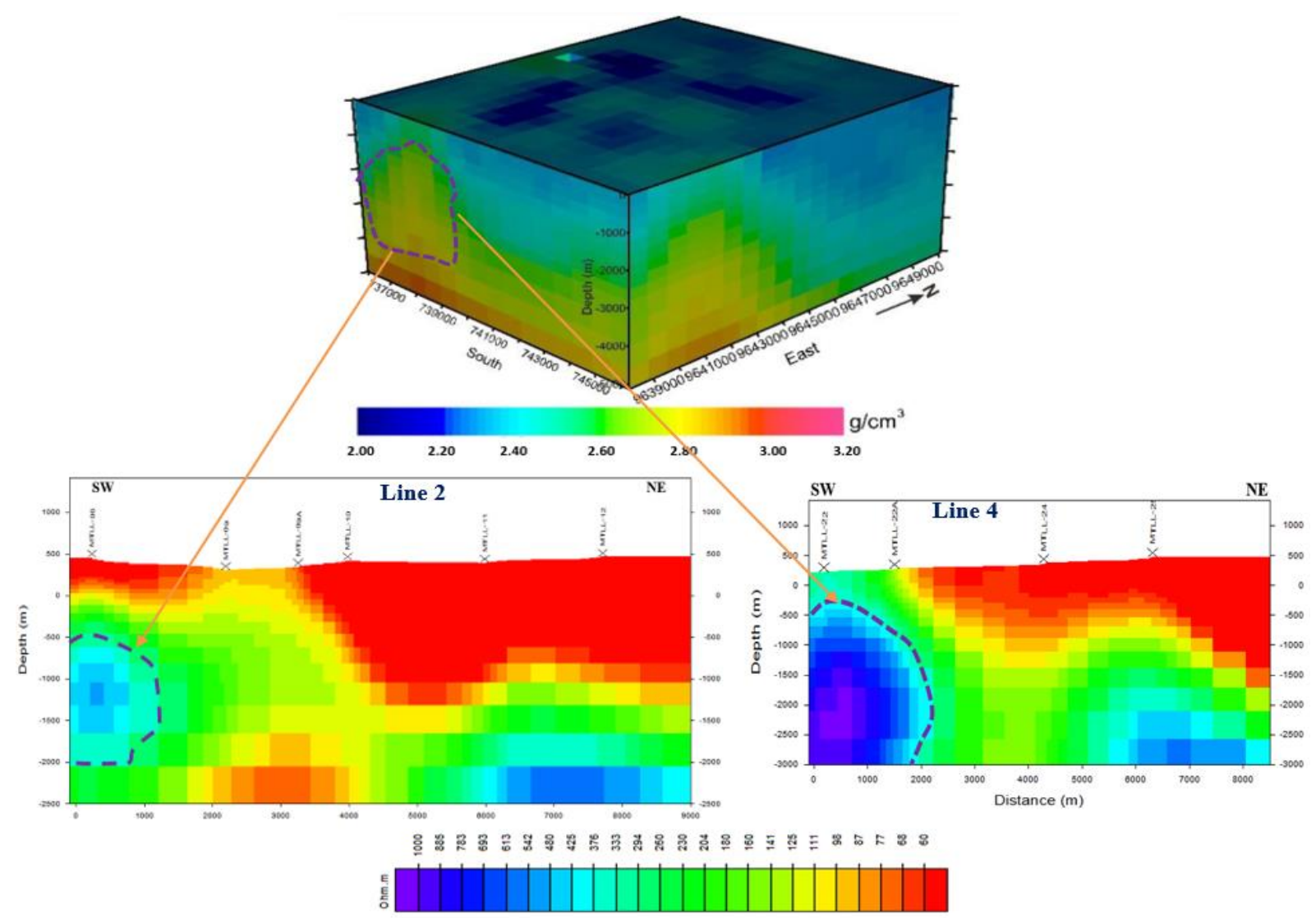

Fig. 13. Interpreted intrusive structure (purple-dotted enclosure) in the south to the southwest of the prospect area. Top: 3D inversion model. Bottom left: Line 2 MT profile. Bottom right: Line 4 MT profile. 
Geochemistry of the spring water indicates that there is an interaction of the geothermal fluid with the rocks through which the fluid passes to the surface and thus the rocks above the reservoir are altered.

A very high resistivity anomaly appears in the south-west end on each of the profiles of Line 2, Line 3, and Line 4. The geology of the area shows that this prospect is associated with plutonism or igneous intrusion; this is most likely responsible for such high anomalies. The 3D inversion model (Fig. 13) also confirms the presence of a very dense protruding structure between the south-west and south of the survey area. The geological model indicates that the metamorphic basement rock starts to appear at a depth of $1900 \mathrm{~m}$ below sea level and therefore cannot correspond to these high resistive structures. Another high-density anomaly exists in the southeast of the survey area. However, MT interprets it as a low resistivity structure.

\section{CONCLUSION}

A drastic reduction in resistivity is witnessed in the survey area both near the surface and at depth confirming the existence of geothermal conditions in the Lili-Sepporaki area. Owing to the assessed geological, geochemical, magnetic, gravimetric, and MT data hydrothermally altered rocks are found at near-surface above the reservoir. The caprock has a resistivity value of less than $100 \Omega \mathrm{m}$. Both the caprock and reservoir occupy the northern, eastern, northeastern, northwestern, and central parts of the survey area. The caprock exists above the reservoir and is constituted of both weathered Walimbong and the inseparable volcanic units. The reservoir appears between depths of 600 and $3400 \mathrm{~m}$ below sea level but is more prominent horizontally between depths of 900 and $1600 \mathrm{~m}$ below sea level. The reservoir deepens towards the east and northwest of the survey area. The highly fractured part of the Walimbong volcanic unit and the porphyritic andesite constitute the reservoir. There is a NW-SE fault structure in the south, responsible for the emergence of Lili-Sepporaki Hot spring. The rock below the reservoir is a typical metamorphic rock owing to both geology and geophysics. An intrusive igneous structure exists between the south and southwest. A high density, low resistivity protruding structure exists in the southeast of the survey area.

Another MT survey with more stations aimed at 3D, 2D, and 1D inversions should be carried out to get a detailed geothermal model of the area. Most studies should also be aimed at elucidating the nature of the dense, low resistive structure in the southeast.

Acknowledgments. The support of the Centre for Mineral, Coal, and Geothermal Resources of Indonesia (PSDMBP), formerly known as the Centre for Mineral Resources (PSDG), is sincerely appreciated. Special thanks go to the Department of Geophysics of PSDMBP for the provision of data, laboratory facility, supervision, and software.

\section{References}

Abfertiawan, M.S., R.S. Gautama, S.B. Kusuma, and S. Notosiswoyo (2016), Hydrology simulation of Ukud River in Lati Coal Mine, EVERGREEN Joint J. Novel Carbon Resour. Sci. Green Asia Strat. 3, 1, 21-31, DOI: 10.5109/1657737.

Biehler, S. (1971), Gravity studies in the Imperial Valley. In: Cooperative Geological-GeophysicalGeochemical Investigations of Geothermal Resources in the Imperial Valley of California, University of California - Riverside Education Research Service, 29-41.

Chau, N.D., W. Klityński, P.N. Phu, and S. Oryński (2019), Application of electromagnetic transient method for $\mathrm{Zn}-\mathrm{Pb}$ exploration at the Cho Dien-Cho Don District, Bac Can Province, North Vietnam, Acta Geophys. 67, 1921-1931, DOI: 10.1007/s11600-019-00350-x. 
Chave, A.D., and A.G. Jones (eds.) (2012), The Magnetotelluric Method: Theory and Practice, Cambridge University Press, Cambridge.

Darma, S., S. Harsoprayitno, B. Setiawan, R. Hadyanto, R. Sukhyar, A.W. Soedibjo, N. Ganefianto, and J. Stimac (2010), Geothermal energy update: geothermal energy development and utilization in Indonesia. In: Proc. World Geothermal Congress 2010, Bali, Indonesia, 25-29 April 2010.

Fauzi, A., S. Bahri, and H. Akuanbatin (2000), Geothermal development in Indonesia: an overview of industry status and future growth. In: Proc. World Geothermal Congress 2000, Kyushu-Tohoku, Japan, 28 May - 10 June 2000, 1109-1114.

Gosh, S.K., and S. Mandal (2018), Evaluation of biogas as an alternative driving force of electrically operated vehicles: a case study, Int. J. Eng. Trans. B: Appl. 31, 5, 834-840, DOI: 10.5829/ ije.2018.31.05b.20.

Gupta, H., and S. Roy (2007), Geothermal Energy: An Alternative Resource for the 21st Century, Elsevier, Amsterdam.

Hall, R., and M.E.J. Wilson (2000), Neogene sutures in eastern Indonesia, J. Asian Earth Sci. 18, 6, 781-808, DOI: 10.1016/S1367-9120(00)00040-7.

Hyndman, R.D., and P.M. Shearer (1989), Water in the lower continental crust: modelling magnetotelluric and seismic reflection results, Geophys. J. Int. 98, 2, 343-365, DOI: 10.1111/j.1365246X.1989.tb03357.x.

Jones, A.G., and I. Dumas (1993), Electromagnetic images of a volcanic zone, Phys. Earth Planet. Inter. 81, 1-4, 289-314, DOI: 10.1016/0031-9201(93)90137-X.

Kholid, M., and S. Widodo (2011), Magnetotelluric and gravity surveys of Lili Matangnga geothermal area, Polewali Mandar Regency, West Sulawesi (in Indonesian).

Martinez-Garcia, M. (1992), Electromagnetic induction in geothermal fields and volcanic belts, Surv. Geophys. 13, 409-434, DOI: 10.1007/BF01903485.

Monroy Parada, A.F. (2016), Phases of geothermal development. In: Proc. SDG Short Course I on Sustainability and Environmental Management of Geothermal Resource Utilization and the Role of Geothermal in Combating Climate Change, UNU-GTPand LaGeo, in Santa Tecla, El Salvador, September 4-10, 2016.

Muffler, L.J.P., and D.E. White (1969), Active metamorphism of upper Cenozoic sediments in the Salton Sea geothermal field and the Salton Trough, southeastern California, Geol. Soc. Am. Bull. 80, 2, 157-182, DOI: 10.1130/0016-7606(1969)80[157:AMOUCS]2.0.CO;2.

Naidu, G.D. (2012), Magnetotellurics: Basic Theoretical Concepts. In: G.D. Naidu, Deep Crustal Structure of the Son-Narmada-Tapti Lineament, Central India, Springer, Berlin Heidelberg, 13-35.

Newman, G.A., E. Gasperikova, G.M. Hoversten, and P.E. Wannamaker (2008), Three-dimensional magnetotelluric characterization of the Coso geothermal field, Geothermics 37, 4, 369-399, DOI: 10.1016/j.geothermics.2008.02.006.

Nurhasan, Y. Ogawa, N. Ujihara, S.B. Tank, Y. Honkura, S. Onizawa, T. Mori, and M. Makino (2006), Two electrical conductors beneath Kusatsu-Shirane volcano, Japan, imaged by audiomagnetotellurics, and their implications for the hydrothermal system, Earth Planets Space 58, 10531059, DOI: 10.1186/BF03352610.

Oryński, S., W. Klityński, A. Neska, and K. Ślęzak (2019), Deep lithospheric structure beneath the Polish part of the East European Craton as a result of magnetotelluric surveys, Studia Geophys. Geodaet. 63, 2, 273-289, DOI: 10.1007/s11200-017-1264-7.

Phoenix Geophysics (2005), Data Processing User Guide. Version 3.0 July 2005, Phoenix Geophysics Ltd.

Prasetyo, B.T., Suyanto, M. Oktaufik, and S. Himawan (2019), Design, construction and preliminary test operation of BPPT-3MW condensing turbine geothermal power plant, EVERGREEN Joint J. Novel Carbon Resour. Sci. Green Asia Strat. 6, 2, 162-167.

Ross, H.P., and J.N. Moore (1985), Geophysical investigations of the Cove Fort-Sulphurdale geothermal system, Utah, Geophysics 50, 11, 1732-1745, DOI: 10.1190/1.1441863. 
Salem, A., D. Ravat, R. Smith, and K. Ushijima (2005), Interpretation of magnetic data using an enhanced local wavenumber (ELW) method, Geophysics 70, 2, L7-L12, DOI: 10.1190/ 1.1884828 .

Sihombing, J., W. Lestari, Mariyanto, and W. Joni (2019), Subsurface analysis using gravity data at Lili Sepporaki geothermal area. In: IOP Conference Series: Materials Science and Engineering, Vol. 588, paper 012009, IOP Publishing Ltd.

Simpson, F., and K. Bahr (2005), Practical Magnetotellurics, Cambridge University Press, Cambridge.

Slezak, K.,W. Jozwiak, K. Nowozynski, S. Orynski, and H. Brasse (2019), 3-D studies of MT data in the Central Polish Basin: Influence of inversion parameters, model space and transfer function selection, J. Appl. Geophys. 161, 26-36, DOI: 10.1016/j.jappgeo.2018.11.008.

Steingrímsson, B. (2015), Geothermal exploration and development from hot spring to utilization. In: Proc. "Short Course on Surface Exploration for Geothermal Resources", UNU-GTP and LaGeo, Ahuachapan and Santa Tecla, El Salvador, 17-30 October 2009.

Tim Survei Magnetotellurik (2011), Final report on the magnetotelluric survey of geothermal survey of LiliSepporaki geothermal area, Number 10/BP/BGD/2011, Center for Geological Resources (in Indonesian).

Tim Survei Terpadu (2010), Integrated geological, geochemical and geophysical investigation of Polewali Mandar geothermal area, West Sulawesi, Center for Geological Resources, Geology Agency of the Ministry of Energy and Mineral Resources-ESDM (in Indonesian).

Ünal İmer, E., I.T. Uysal, E. St Pierre, J.X. Zhao, and J. Shulmeister (2020), Last glacial climate oscillations and sudden environmental changes investigated in stalagmites from southwest Sulawesi, western Pacific, Turkish J. Earth Sci. 29, 221-241, DOI: 10.3906/yer-1905-20.

Unsworth, M. (2002), The Role of crustal fluids in strike-slip tectonics: new insights from magnetotelluric studies, Turkish J. Earth Sci. 11, 193-203.

Van Leeuwen, T.M. (1981), The geology of Southwest Sulawesi with special reference to the Biru area, Geol. Res. Dev. Cent. Sp. Publ. 2, 277-304.

Wright, J.B., D.A. Hastings, W.B. Jones, and H.R. Williams (1985), Geology and Mineral Resources of West Africa, George Allen \& Unwin Publ., London, DOI: 10.1007/978-94-015-3932-6.

Wulandari, D.A., E. Nasruddin, and E. Djubaedah (2019), Thermal behavior and characteristic of Pangandaran natural zeolite, EVERGREEN Joint J. Novel Carbon Resour. Sci. Green Asia Strat. 6, 3, 225-229, DOI: 10.5109/234298.

Zhu, W., C. David, and T.F. Wong (1995), Network modeling of permeability evolution during cementation and hot isostatic pressing, J. Geophys. Res. 100, B8, 15451-15464, DOI: 10.1029/ 95JB00958.

Received 21 April 2020

Received in revised form 26 May 2020

Accepted 30 June 2020 